\title{
An Interdisciplinary Approach to Investigate Preschool children's Implicit Inferential Reasoning in Scientific Activities
}

\author{
Josephine Convertini ${ }^{1}$ \\ Published online: 25 August 2020 \\ (C) The Author(s) 2020
}

\begin{abstract}
The implementation of Science, Technology, Engineering, and Mathematics (STEM) at school is one of the challenges of education in the twenty-first century, especially concerning the development of critical thinking during argumentative interactions. In this paper, I refer to an interdisciplinary approach with the aim to analyze the implicit inferential reasoning emerging in argumentative discussions among children during scientific activities. The study involved 25 preschool children at a kindergarten engaged in three problem solving tasks. The first activity was to build a tunnel, the second to build a bridge - both with the use of Lego@ — and the third to build an hourglass with recycled materials. The tasks were video-recorded and the discussions transcribed. The analysis implied different steps: first, I identified the argumentative structure of each exchange according to the pragma-dialectical approach; then, I found the implicit premises using the Argumentum Model of Topics; afterward, I analyzed the argumentative discussions according to a sociocultural approach. The findings show a predominance of arguments based on causal relationships and indicate how children reason regarding complex aspects of a problem, such as the negative consequences of an action, the adequacy of the available tools, and the (possible) future conditions connected to the scientific activity they are involved in. The study opens a possibility to shift from how to implement STEM activities to what children already do when engaged in scientific tasks. It also encourages the adoption of an interdisciplinary approach to investigating the complex process of argumentation in preschool children.
\end{abstract}

Keywords Preschool children's reasoning · Problem solving · STEM · Implicit argumentation · Adult-children discussion

Josephine Convertini

josephine.convertini@supsi.ch

1 Department of Education and Learning, University of Applied Sciences and Arts of Southern

Switzerland (SUPSI), Locarno, Switzerland 


\section{Introduction}

The implementation of STEM at school is one of the challenges of education in the twenty-first century for many countries (Sanders 2008). The reflection of specialists approaching the world of STEM can be grouped into three categories: (1) what STEM is within disciplines concerning subjects that are interrelated; (2) how STEM is implemented and analyzed in education; and (3) why STEM is relevant to fulfill the young citizens' needs and to prepare them for a future in society (Bybee 2013).

This paper intends to contribute to the debate concerning how STEM is analyzed. Within this frame, a relevant point concerns the distinction between the "knowledge of science" and the "knowledge about science" (Kim et al. 2012). The first one refers to a set of knowledge on scientific contents such as the notion of speed or the mechanism behind shadow formation. The second one is related to the critical thinking and the scientific activities including argumentative processes. The perspective assumed here will focus on the latter and, more particularly, on the investigation of reasoning in scientific activities. ${ }^{1}$

Regardless of the specific STEM's field, argumentation is in fact a transversal process of knowledge construction about the natural world (Erduran and Jiménez-Aleixandre 2008). It is also a process of critical reasoning that is important for the development of young citizens (Schwarz and Baker 2017). In this paper, the knowledge about science will be explored by the adoption of an interdisciplinary approach aiming at analyzing the types of argument (or implicit inferential reasoning) emerging in situations in which preschool children are asked to solve a task together. The focus on the implicit aspects of argumentation is justified by the evidence that not the entire inferential reasoning of children is explicit (Perret-Clermont et al. 2019). Looking at these types of arguments in children's discourse can offer a useful contribution about how they reason during scientific activities within problem solving situations (Convertini 2019).

The paper is organized as follows: first, I briefly review the existing studies connecting argumentation, reasoning and scientific activities. Then, I introduce the interdisciplinary approach considered to study argumentative inferences in young children. After the presentation of the empirical study, the discussion of the findings and a conclusion will close the paper.

\section{Argumentation in Scientific Activities}

The literature on scientific activities in education and in particular in early childhood is relatively recent (Impedovo et al. 2017). Most of the studies about how to implement and analyze STEM in education deal with elementary, middle or high school (e.g., Smyrnaiou et al. 2015). Within this frame, argumentation can play an important role in scientific activities, also in preschool children. As the mind is argumentative by nature (Moshman 2004), young children are naturally inclined to explore the environment and to ask questions about scientific phenomena (Danish and Enyedy 2015; Ravanis 1994). Argumentation is considered a main feature of scientific activities because it is a process of critical reasoning related to knowledge construction (Duschl and Osborne 2002; Erduran et al. 2004). This relation is very strong

\footnotetext{
${ }^{1}$ This study is part of the research project "Analyzing children's implicit argumentation: Reconstruction of procedural and material premises," funded by the Swiss National Science Foundation (project n. 100019_156,690).
} 
according to Osborne (2010): "critique is not, therefore, some peripheral feature of science, but rather it is core to its practice, and without argument and evaluation, the construction of reliable knowledge would be impossible" (p. 464). The introduction of the study of argumentation in scientific education is the result of a shift in researchers' attention from what we learn to how we learn (Duschl 2007). In fact, science education includes the processes of understanding how children argue and how the different speakers' ideas are interrelated (Sampson and Clark 2009).

A key process of argumentation is the inference, namely a reasoning that allows reaching certain conclusions even without a direct experience of them (Rigotti and Cigada 2004). When two or more speakers provide an argument, they are engaging in a process of critical reasoning. The same conclusion can be drawn by appealing to different arguments and to different sources of information. Although inference is a core reasoning process in argumentation, it remains usually implicit (Greco et al. 2018), because the speakers do not have to explicitly explain every piece of information in order to communicate effectively with each other. On the contrary, some redundancy should be considered as a factor hampering the cooperation in conversation (Grice 1975). In argumentative activities in scientific education, students are often required to argue and to explicitly explain their reasoning (Lazarou 2009). In fact, it could be difficult to evaluate the children's standpoints without knowing what the rationale is behind their answers (Lombardi et al. 2018). Their implicit inferential reasoning is then an interesting object of investigation. For this reason, in the next section the focus is on the available theoretical tools to analyze the preschoolers' implicit inferential reasoning.

\section{Preschoolers' and Students' Implicit Steps of Reasoning}

The reconstruction of argumentative patterns of reasoning should be considered a useful tool to analyze conversations (Macagno and Walton 2006) among students in science classrooms.

Traditionally, implicit logical steps of argumentation in scientific activities have mostly been studied through the Toulmin's model (Erduran et al. 2004) and the Walton's pragmatic approach (e.g., Ibraim et al. 2013). The latter has received particular attention in the past few years. For example, Konstantinidou and Macagno (2013) analyzed students' written argumentations about thermal conductivity by following the Walton's approach. They defined the argumentation schemes as "abstract forms of the most used and common forms of human reasoning, combining logical principles with semantic concepts" (p. 1069). As the model was used to reconstruct the premises underlying the students' argumentation and to explore the background knowledge, the authors found that most of the schemes rely on a "cause to effect" model, as well as a minority belonging to the analogy principle. These findings were interpreted as a consequence of the type of activity in which students were asked to reflect.

In another study, Macagno and Konstantinidou (2013) investigated the argumentation schemes and the background knowledge of students by analyzing written argumentations around a task of physics. The authors found a majority of arguments related to causality and analogy. Other scholars (Ibraim et al. 2013) applied the argumentation schemes to the arguments of four medium level students involved in daily-based and in scientific problems, before and after a modeling-based teaching. The authors used the classification of argumentation schemes proposed by Walton et al. (2008), by grouping the argumentation schemes in similar classes. The results showed that most of the argumentation schemes belong to the hypothetical reasoning. In the case of scientific problems proposed after the modeling-based 
teaching, the most frequent scheme was from cause to effect. This result was explained by the authors as a consequence of the scientific nature of the problems they selected. The argumentation schemes related to the evaluation of alternative options emerged only when the scientific problems were proposed after the modeling-based teaching, because the students were asked to compare different explanatory models.

Other scholars inductively created some categories of arguments and studied preschool children argumentation in different situations. Migdalek et al. (2014) found a higher number of arguments by which children propose alternative solutions to a given problem. Banks-Leite (1998) studied argumentation in preschool children by reconstructing the warrant in terms of the connection between a claim and evidence (cf. Toulmin 1958). She investigated episodes of spontaneous argumentation emerging during dialogs between a teacher and preschool children. The aim of the study was to explore how young children refer to the warrant component of argumentation. As a result, five different warrants in children's arguments were identified as signs of how young children are able to present very elaborate arguments.

The variety of approaches briefly reported here indicates how relevant the investigation of children's argumentative inference is. However, the large set of tools and approaches seems to favor a kind of "dispersion" of resources that could be useful to integrate, when possible. For this reason, in this paper I propose to focus on a combination of analytical tools elaborated within an interdisciplinary frame in order to study how children reason during scientific activities.

\section{An Interdisciplinary Approach to Study Argumentative Inferences}

In this section, I propose to combine two analytical tools borrowed from modern and contemporary argumentation theories: the pragma-dialectical approach (van Eemeren and Grootendorst 1984, 2004) and the Argumentum Model of Topics (Rigotti and Greco 2019; Rigotti and Greco Morasso 2009), hereafter AMT. Recent investigations conducted by Greco et al. (2018) on the misunderstandings between children and adults in argumentative discussions and the work done by Perret-Clermont et al. (2019) on the children's active contributions to critical discussions already suggested the potential of integrating these tools to analyze how children reason.

In addition, I intend to invoke the socio-cultural perspective to look at how argumentation is co-constructed during interaction and how it is anchored to its context of production (Åberg et al. 2010).

The first tool is the pragma-dialectical model of a critical discussion, which aims at reconstructing argumentative discussions and at establishing the argumentative structure of a dialogue. The model proposes an analysis of argumentation through different steps (analytical overview) aiming at identifying: the standpoints; the roles of participants (antagonist and protagonist); the procedural and material (implicit or explicit) premises; the rules of discussion; the arguments supporting the standpoints; the argumentative structure for each standpoint that indicates the specific relation between the arguments and the standpoint; and the argumentation scheme for each argument that describes the inferential principles connecting arguments and standpoint. With respect to this tool, I propose two major adjustments of the analytical overview. First, I will avoid qualifying the participants in terms of protagonist and antagonist. In fact, scientific activities are often proposed by the adult and, by consequence, children rarely have a pre-established standpoint on a topic that is supposed to be investigated at school. As highlighted by Nonnon (2015), standpoints are not the starting points in a classroom debate, 
but they are co-constructed step-by-step by the participants, who collaborate and continually change their argumentative roles (Hannken-Illjes and Bose 2018). Second, the implicit inferential principles connecting arguments and standpoint are not considered by applying the argument schemes. The reasons for this choice are explained below.

The second tool is the AMT, which aims at reconstructing the inferential configuration of the argumentation. The model distinguishes between premises of inferential-procedural nature (the logical principle of the reasoning) and premises of contextual-material nature (the knowledge that is supposed to be shared by speakers). In this way, the inferential connection is always anchored to the real situation in which the argumentation is developed (Rigotti and Greco Morasso 2010). The contextual-material component is divided into the endoxon and the datum. The former is the knowledge that is supposed to be shared by speakers, while the latter is the factual information. The inferential-procedural component includes the locus that indicates the semantic-ontological relation at the basis of a reasoning and the maxim designating the inferential connection originating from the locus.

The main reasons for combining the two tools in the investigation of children's implicit inferential reasoning are the following: making explicit the standpoint and the arguments through the pragma-dialectics enables extrapolating the argumentative elements of the discussion useful for the analysis. Moreover, the argumentative structure enables making explicit the number of arguments and their relationships with the standpoint and therefore to obtain an insight regarding the complexity of children's reasoning. Nevertheless, it is only by applying the argumentation scheme that it is possible to make explicit the implicit premises of argumentation and to further investigate the children's reasoning. Although the pragma-dialectical model identifies three argumentative schemes and different subtypes of argument schemes, the AMT model is here adopted to reconstruct the inferential configuration of argumentation because it allows differentiating the implicit premises of different nature in a systematic way (Rigotti and Greco Morasso 2010). In fact, the AMT has the advantage of making a clear distinction between the inferentialprocedural and the material-contextual components, as well as between the locus and the other components of the inferential-procedural axis.

\section{Goal of the Study}

The aim is to identify the implicit inferential reasoning emerging in argumentative discussions among preschool children involved in scientific activities.

\section{The Empirical Study}

\section{Participants and Procedures of Data Collection}

The research was carried out in a kindergarten in Italy during Autumn 2016. ${ }^{2}$ A group of 25 children ( male $=13$; female $=12$ ) aged between 3 and 5 (average age $=4: 8$ years old) participated in the study. Prior to the data collection, the researcher participated with the children and the teachers in the daily activities of the kindergarten for a week. This period allowed children to become familiar with the observer and vice versa. Before the data collection, the researcher

\footnotetext{
${ }^{2}$ For more details regarding the research presented in this article, see Convertini (2019).
} 
obtained all the necessary permissions, according to the ethical code guaranteed throughout the entire research process.

According to the total number of participants, children were grouped in small groups (7 triads and 2 dyads) in the idea of soliciting the children's reasoning through situations of sociocognitive conflict (Perret-Clermont 1979/1996). Each triad and dyad were asked to solve three tasks: building a tunnel with Lego@ $\odot$ blocks in such a way that a specific toy car can drive through it (activity 1); building a bridge with Lego@ in such a way that two friends (two LEGO® characters) who live on opposite sides of a lake (a blue poster) can meet each other (activity 2); building an hourglass with recycled materials (activity 3 ). ${ }^{3}$ The tasks were connected to STEM as the children were involved in engineering/physical tasks (building), through science processes (inquiry and problem solving) and referring to scientific notions (height, length, and weight). The design was intended to invite children to adopt standard or innovative ways of using the tools (Lego@) or recycled materials) to jointly solve the problem.

The activities were video recorded (by placing a camera in front of the groups' worktable) to catch verbal and nonverbal elements useful for a following analysis performed by the researcher. At the end, 27 recordings were collected for a total of about $16 \mathrm{~h}$ of videorecordings. In addition, an audio-recorder was placed on the worktable of each group to better capture the children's voices.

\section{Procedures of Data Analysis}

The software Transana Basic 3.10b was used to select the episodes of argumentative discus$\operatorname{sion}^{4}$ within the recorded data. These episodes $(N=65)$ were transcribed using a simplified version of the system elaborated by Jefferson (2004). Transcriptions also included non-verbal elements, such as the position of the tools and the participants' gestures. Based on the transcripts, the argumentative structure of each argumentation found within an episode was established through the pragma-dialectics. Then, the locus through which each argument supports a standpoint was identified by referring to the classification of Rigotti and Greco (2019). Finally, the implicit premises were detected through the AMT.

\section{Results}

A total of 89 children's argumentations were identified in the corpus, and classified in six cases of multiple argumentative structure, 12 cases of subordinative argumentative structure, three cases of coordinative argumentative structure, and 68 cases of simple argumentative structure. A total of 110 arguments were identified. The most frequent locus through which the children's arguments supported the standpoint was "causal" (66 cases, with a prevalence 47 cases - of locus "from the final-instrumental cause") followed by "definitional" loci - 19 cases. In line with previous studies (e.g., Ibraim et al. 2013), this result was in part predictable, because of two elements: (1) the scientific nature of the chosen tasks; (2) the fact that children were asked to use the available tools (Lego@ and recycled materials) to solve the problem. In

\footnotetext{
${ }^{3}$ These activities were inspired by Piaget $(1974,1980)$ and by the foundation La main à la pâte. See http://www. fondation-lamap.org/en/international, last view: June 2020.

${ }^{4}$ Within the present study, an argumentative discussion is an episode where an issue is discussed via presentation of one or more argumentation.
} 
other words, the assignment of the activities suggested a process of reasoning connecting instruments and goals.

To better investigate this result, the inferential configuration of each argumentation was reconstructed and described by the different components in the AMT. As the present study intends to strengthen the combination of different approaches used to analyze scientific argumentative discourses, the focus on methodology constitutes a critical aspect of the investigation of implicit premises. To emphasize the role of the methodological tools in describing the argumentative processes constructed by the children, I present a couple of illustrative cases in which the same locus was identified.

\section{Case 1: The Toy Shovel}

Three children are working together to build an hourglass with recycled material, ${ }^{5}$ including a smallscale model of the object, two little plastic bottles, a plastic box containing sand, three small spoons, a tape, a pair of scissors, and three funnels. The researcher presents the materials to the children and then asks them to build an hourglass. She lets them work together while remaining in the room, to help them in case of need. Children start to manipulate the tools by observing and touching them. After 15 min, although the children already filled one of the plastic bottle with the sand, they ask the adult to join the worktable and to help them. Excerpt 1 concerns the moment in which the researcher joined the group and start interacting with children.

When the adult proposes to work together, she does not make explicit her argument and Tom raises a doubt (we cannot work together). ${ }^{6}$ This standpoint is implicit and presents an argument 1.1 (the adult does not have the shovel). ${ }^{7}$ The argumentative structure of this first argumentation is simple because there is only one argument supporting the standpoint. Within the frame of a sociocultural approach, the argumentation is the result of a co-construction: in turn 6, the adult is focused on the goal of the activity, while Tom (turn 9) advances an implicit standpoint, opposed to those proposed by the adult. In fact, the child says that it is impossible to work together, because the researcher does not have a shovel (changing the focus of attention to the material). In turn 14, the adult asks "What do we do"? suggesting the need to focus on the goal of the activity. In response to this intervention, Tom changes his opinion, by aligning himself to the adult's standpoint and advancing the argument 2.1 (the adult can use the hands, the fingers). The argumentative structure of this second argumentation is subordinative because the argument 2.1 is supported by another argument 2.1.1.

The Fig. 1 presents the argumentative structure of Tom's argumentation. During the activity, the children ask the adult to help them. Accordingly, the researcher shows a model of an hourglass, asking the children to compare it to their product. As Lena and Sara indicate that there is no correspondence between the two hourglasses, the adult proposes to work together ("Let's do it step by step together" - turn 6). Sara underlines in an explicit way that together means to involve all four participants ("Together, four of us" - turn 7), confirmed by the intervention of the adult in turn 8 ("four of us, shall we?"). At this point, before starting the

\footnotetext{
${ }^{5}$ This activity was designed in collaboration with the teacher based on previous pedagogical activities conducted in the classroom about the notions of hourglass and time measurement.

${ }^{6}$ According to the rules of the critical discussion, one has to support his/her standpoint through one or more arguments, especially when the other participants raise doubts. In this extract, the adult, differently from Tom's performance, seems to act against the required standard of reasonableness.

${ }^{7}$ Although the standpoint is implicit, in turn 9 the adversative connective "but" plays a central role in helping to detect the argumentation (Rocci et al. 2020).
} 
Excerpt 1 Discussion between Lena (5 years old), Tom (5:4 years old), Sara (5:7 years old), and the researcher

\begin{tabular}{|c|c|c|c|}
\hline Turn & Speaker & Original Italian transcription & English translation (verbatim) \\
\hline \multicolumn{4}{|c|}{$(0: 15: 56.4)$} \\
\hline 1 & Researcher & $\begin{array}{l}\text { guardate un pò qua ((mostrando la } \\
\text { clessidra)) ci assomiglia? } \\
\text { ((al lavoro fatto dai bambini }))\end{array}$ & $\begin{array}{l}\text { look at this ((showing the hourglass)) does it look } \\
\text { similar? ((to the work already done by the } \\
\text { children }))\end{array}$ \\
\hline 2 & Lena & no ((guarda la clessidra)) & no ((she looks at the hourglass $))$ \\
\hline 3 & Sara & no ((guarda la clessidra)) & no ((she looks at the hourglass $))$ \\
\hline 4 & Researcher & cosa cosa volete fare allora? & what what do you want to do then? \\
\hline 5 & Lena & vogliamo fare & we want to do \\
\hline 6 & Researcher & facciamo passo passo insieme & let us do it step by step together \\
\hline 7 & Sara & $\uparrow$ insieme tutte e quattro & $\uparrow$ together four of us \\
\hline 8 & Researcher & tutti e quattro vi va? & four of us shall we? \\
\hline 9 & Tom & $\begin{array}{l}\text { [ma te non c'hai la paletta } \\
\text { ((indica i cucchiaini)) }\end{array}$ & $\begin{array}{l}\text { [but you do not have the shovel } \\
\text { ((he points the little spoons)) }\end{array}$ \\
\hline 10 & Sara & $\begin{array}{l}\text { [allora un pochino la dobbiamo } \\
\text { rovesciare ((versa la sabbia nel } \\
\text { contenitore) })\end{array}$ & $\begin{array}{l}\text { [then we are gonna have to spill it a little bit } \\
\text { ((she pours the sand in the box }))\end{array}$ \\
\hline 11 & Researcher & come? & sorry? \\
\hline 12 & Tom & non c'hai la paletta & you do not have the shovel \\
\hline 13 & Sara & $\begin{array}{l}\text { ne metto ancora un pochino } \\
\quad((\text { di sabbia }))\end{array}$ & I'll put a little more ((of sand)) \\
\hline 14 & Researcher & $\begin{array}{l}\text { e come facciamo? } \\
\quad((\text { guarda il contenitore }))\end{array}$ & how do we do? ((she looks the box $))$ \\
\hline 15 & Sara & così ((finisce di versare la sabbia)) & like this ((she finished to pour the sand)) \\
\hline $\begin{array}{l}16 \\
(0: 16: 2\end{array}$ & Tom & fai con le mani con le dita & do it with your hands with your fingers \\
\hline
\end{tabular}

To ensure the participants' anonymity, all names indicated in the excerpts presented in this paper are pseudonyms.

joint work, Tom raises a doubt: "But you don't have the shovel" and points the spoons. This action overlaps the Sara's voice: "Then we're gonna have to spill it a little bit" (turn 10) and produces a couple of repetitions (turns 12 and 13) about how to proceed. Then, the researcher asks for a clarification ("What do we do?" - turn 14). The children express their position: Sara indicates to do "like this" (finishing to pour the sand), while Tom says "Do it with your hands, with your fingers" (turn 16). This is a case of cumulative talk (Mercer 1995) characterized by repetitions and accumulation of idea. More precisely, Sara is putting the attention on the sand contained in the bottle and in the box, while the adult and Tom are discussing the issue - can

\begin{tabular}{l}
\hline (We cannot work together) \\
$\begin{array}{l}\text { Adult } \\
\text { (We can work together) - } \\
\text { Let's do it step by step, } \\
\text { together (turn 6) }\end{array}$ \\
(turn 9)
\end{tabular}

Fig. 1 Analytical overview of the argumentation (excerpt 1) 
we work together? When the adult asks "How do we do?" (turn 14), Sara answers by showing how to pour the sand, and Tom also replies to the adult ("Do it with your hands, with your fingers" - turn 16).

Figure 2 presents a reconstruction of the inferential configuration of the first argumentation advanced by Tom.

In the first argumentation, the locus is from final-instrumental cause. The maxim is the following: "if not everybody have the necessary tool to achieve the goal, the goal cannot be achieved." Tom is reasoning about the impossibility to reach the goal (to work together) in relation to the adequacy of the instruments (the number of little spoons provided by the adult in relation to the number of participants). At the beginning of the activity, the researcher provides to the children three funnels and three little spoons (one per child). For this reason, the endoxon is the following: "working together requires that everyone has the shovel." The endoxon is supposed to be shared by speakers. The problem is that the adult asks children to work together with her, although she does not have a shovel (this is the datum). From his perspective, the child can conclude that it is not possible to work together (final conclusion). The adult and the children do not share the same narrative scenario (Iannaccone et al. 2019). In fact, while the issue of the researcher exclusively considers her goal (building an hourglass), Tom adds an aspect hitherto ignored (the tools needed to work together).

Figure 3 presents the reconstruction of the inferential configuration of the second argumentation advanced by Tom.

The second argumentation is the result of two arguments. The AMT makes explicit the way in which they are interconnected. The first argument (2.1: "the adult can use the hands, the fingers") supports the standpoint by the locus from final instrumental cause. The maxim is "if the instrument I to achieve the goal G is available, then G can be achieved." As in the first argumentation, Tom is reasoning about the possibility to achieve the goal (working together) in relation to the tools (using hand and fingers). What is more interesting in the difference between the first and the second of Tom's argumentation is the endoxon. In the first case it was: "working together requires that everyone has the shovel" and in this case is: "working together requires using the hand, the fingers." Through this confrontation, we can observe a shift in the way in which the goal can be achieved according to Tom's reasoning. Since the first solution does not allow the adult to participate in the activity and since the adult is suggesting that they have to work together (the conclusion cannot be changed), Tom reconsiders his reasoning by changing the premises. In this way, he aligns his reasoning to the adult's requests. The second argument (2.1.1: "the adult does not have the shovel") supports

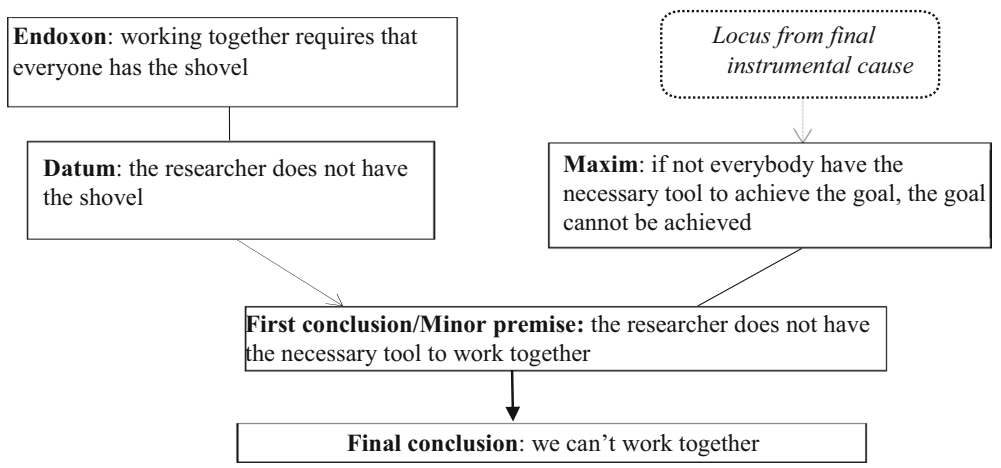

Fig. 2 Inferential reconstruction of the first argumentation advanced by Tom 


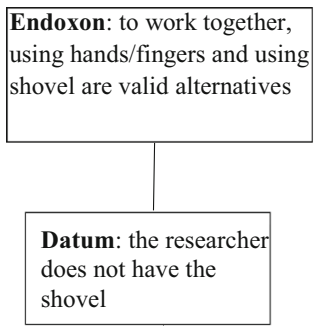

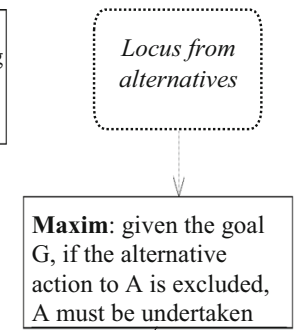

A must be undertaken

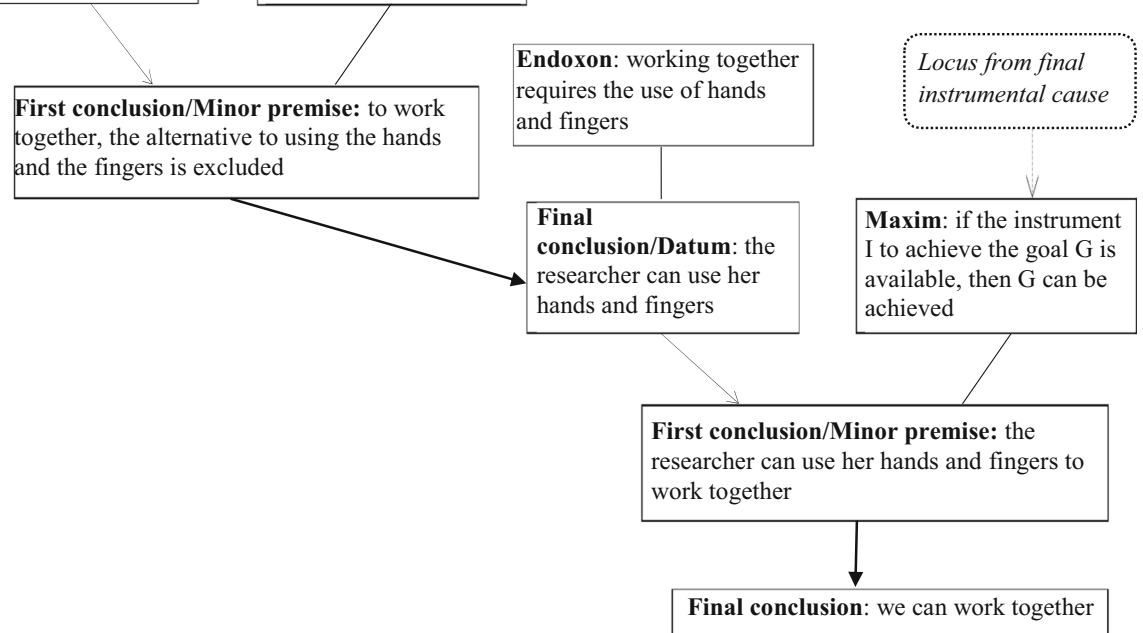

Fig. 3 Inferential reconstruction of the second argumentation advanced by Tom

the standpoint 2.1: "the researcher can use her hand, her fingers" by the locus from alternatives. The fact that the adult does not have the shovel is evidence (datum). For this reason, Tom has to suggest another tool (hands/fingers). However, to legitimize this changing, he has to reason on the fact that the second option is a valid alternative to the first tool.

The reconstruction of the argumentative structure of Tom's argumentations through the pragma-dialectics enabled extrapolating the argumentative elements of the discussion and to make explicit the relation between standpoint and arguments. Moreover, it allowed identifying a shift in the child's perspective. The AMT allowed investigating this result in a deeper way, in terms of "knowledge about science" (Kim et al. 2012) and of the children's capacity to assume a scientific attitude. The inferential configuration showed how children are able to reason about the possibility/impossibility to achieve a goal in relation to the tools. Children managed to reason about valid alternative solutions to a given problem. The analyses indicate that they were able not only to change their standpoints during the (short) discussion but also to reason about their premises. It was the case for Tom who proposed a standpoint and an argument to support it, and finally argued for another standpoint (the one of the adult), by changing the premises. Children were able to have their arguments rely on others' standpoints and to consider, at the same time, the role of the tools provided by the adult.

\section{Case 2: Do Not Jump!}

The same group of three children has already filled one of the plastic bottles with sand. Then, they try to stick the bottles with tape. During their previous attempts, the children tried 
different strategies: they added more tape or tried to push the bottles toward each other by beating other objects on the top of the bottles. The children were working together: while one child held the bottles with his/her hands, the other picked the pieces of tape, and another fastened them to the two bottles.

Excerpt 2 starts immediately after the moment in which Lena finished to cut a piece of tape and passed it to Sara. Then, Lena puts her hands on the table and starts to jump.

The aim of the task is still to build an hourglass. To achieve the goal, one of the two bottles must be filled with sand, while the second bottle must be turned upside down on the first bottle. Then, the two bottles must be sealed together with the tape. At the end of the activity, the two bottles will be in a vertical position.

During the exchange, Lena states that they have done it (turn 1), because, contrary to the previous attempts, the two bottles remained in a vertical position without falling. In turn 5 , Lena puts her hands on the table and starts to jump. As reaction, Sara presents the standpoint "Lena, don't do like that" and supports it by adding an argument (otherwise the funnel will fall). As the hourglass fell, Lena stops jumping.

Figure 4 presents the argumentative structure of the argumentation advanced by Sara in turn 6.

The argumentative structure is simple because only one argument supports the standpoint by means of the locus from final-instrumental cause. The instrument, in this case the action of Lena (to jump on the table), is related to the goal (the bottles need to be in a vertical position).

Figure 5 shows the AMT's reconstruction of the inferential configuration of Sara's argumentation.

In the argumentation presented above, the locus is from final-instrumental cause. The maxim is the following: if an action has negative consequences, then it must not be undertaken. Lena's action of jumping caused the inclination of the hourglass on which the children were working. For this reason, Sara advances an argumentation as a response to the action of Lena. In the specific case, the argumentation is solicited

Excerpt 2 Discussion between Lena (5 years old), Tom (5.4 years old), Sara (5.7 years old), and the researcher

Turn Speaker Original Italian transcription

\begin{tabular}{|c|c|c|c|}
\hline \multicolumn{4}{|c|}{$(0: 22: 20.9)$} \\
\hline 1 & Lena & $\begin{array}{l}\text { abbiamo formato ((Sara allontana le mani } \\
\text { dalle bottigliette e queste restano in piedi)) }\end{array}$ & $\begin{array}{l}\text { we have done it ((Sara takes her hands away } \\
\text { from the bottles and they remain standing)) }\end{array}$ \\
\hline 2 & Sara & sembra un imbuto & it looks like a funnel \\
\hline 3 & Lena & io lo taglio ((taglia un pezzo di scotch)) & I'll cut it up ((she cuts a piece of tape)) \\
\hline 4 & Sara & volete che sembra un imbuto? & you want it to look like a funnel? \\
\hline 5 & Lena & $\begin{array}{l}\text { (h) ((Lena sta saltando e tiene le mani } \\
\text { appoggiate sul tavolo di lavoro) })\end{array}$ & $\begin{array}{l}\text { (h) ((Lena is jumping and holding hands) } \\
\text { resting on the work table)) }\end{array}$ \\
\hline 6 & Sara & $\begin{array}{l}\text { Lena, non fare così sennò cade l'imbuto ((la } \\
\text { costruzione si inclina)) }\end{array}$ & $\begin{array}{l}\text { Lena, do not do like that otherwise the funnel } \\
\text { will fall down ((the construction tilts)) }\end{array}$ \\
\hline 7 & Tom & oh:: ((guarda la costruzione $))$ & oh:: ((he looks at the construction)) \\
\hline 8 & Sara & $\begin{array}{l}\text { è già caduto l'imbuto ((le bottigliette si } \\
\text { dividono e Lena smette di saltare)) }\end{array}$ & $\begin{array}{l}\text { the funnel is already fall down ((the little bottles } \\
\text { are separated)) }\end{array}$ \\
\hline 9 & Tom & non si trova più ((è finito lo scotch)) & cannot find it anymore ((there is no more tape $))$ \\
\hline 10 & Sara & cosa non si trova più? & what is missing? \\
\hline 11 & Tom & quello ((indica lo scotch)) & that one ((he indicates the tape $))$ \\
\hline \multicolumn{4}{|c|}{$(0: 22: 41.8)$} \\
\hline
\end{tabular}


Fig. 4 Analytical overview of the argumentation (Excerpt 2)

\section{Sara}

1 Lena must stop to jump on the table (turn 6)

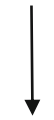

1.1 otherwise the funnel will fall (turn 6)

not only by verbal propositions but also by nonverbal elements (the action of Lena). These contribute to the difference of opinion on what should be appropriate to do. Sara's reasoning is about the side-effect of the action: when the children managed to weld the bottles, Lena's behavior neutralized the benefits they already achieved. According to this, the minor premise is the following: "the fact that Lena jumps on the table could have negative consequences." This is also a prediction advanced by Sara about the possible effects on the objects, in relation to the partner's behavior. The endoxon expresses information related to the "background" (in this case, a physical relation) based on previous experiences made by the children. This allows Sara to create a relation between the ongoing event (the oscillation of an object) and the prediction of a future event (the object will fall). The datum concerns the ongoing factual event: Lena jumps on the worktable where there is also a funnel that is about to fall.

The pragma-dialectics allows identifying the argumentative elements useful for the analysis and to make explicit a "simple" argumentation. However, the reconstruction of the inferential configuration of the argumentation through the AMT shows the complexity of the argumentation and the children's "scientific" participation in the activity. Children were able to reason about the negative consequences of an action. They made predictions about future (possible) physical conditions and were able to reason about the elements that can prevent reaching a certain goal. Within a sociocultural perspective, the analysis also highlights how the children's interventions are interrelated and, more particularly, to what extent Lena's action became part of Sara's reasoning.

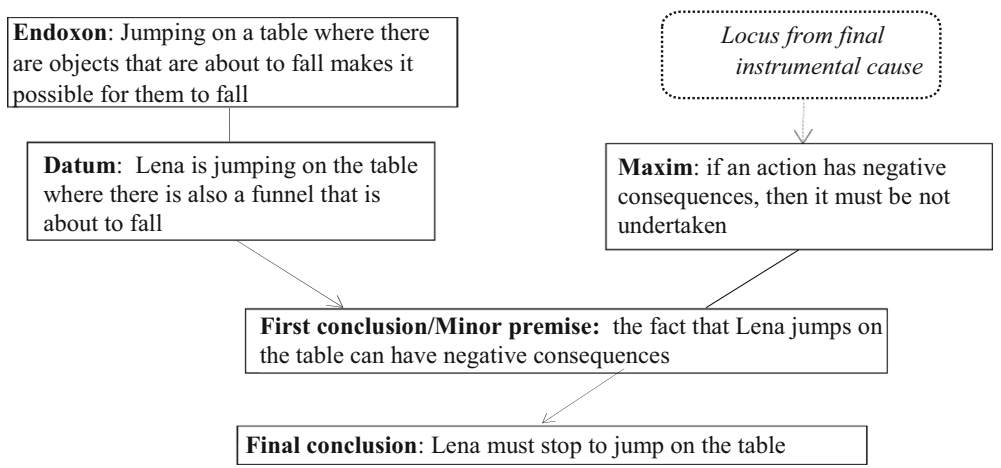

Fig. 5 Inferential reconstruction of the second argumentation advanced by Sara 


\section{Discussion and Conclusion}

In the past few decades, scientific education went through a significant shift in researchers' attention from what we learn to how we learn (Duschl 2007). This transition required the analysis of argumentation processes in scientific discourse as processes of critical reasoning. More particularly, inference plays a central role in the construction of children's - and students'-knowledge (Duschl and Osborne 2002; Erduran et al. 2004; Orsolini and Pontecorvo 1992). Because inference in argumentation is often implicit (Bova et al. 2017; Perret-Clermont et al. 2019), I advanced the thesis that it is relevant to combine tools belonging to different disciplines (theories of argumentation, linguistics, psychology, education) in order to make these inferences explicit. Other authors already investigated the types of arguments in children's or students' discussions, applying the Toulmin's model (Banks-Leite 1998), the Walton's pragmatic approach (Ibraim et al. 2013) or other categories (Migdalek et al. 2014). These studies identified how arguments based on causal relationships are very frequent in science.

However, to move a step forward within this frame, in this paper I analyzed the implicit inferential reasoning of young children through other lenses. First, I referred to the pragmadialectical approach to establish the structure of argumentations, by making explicit the relationship between standpoint and arguments and getting an insight into the complexity of children's reasoning. Then, the locus through which each argument supports a standpoint was identified (Rigotti and Greco 2019). Finally, I used the AMT as a helpful tool to reconstruct the inferential configuration of the argumentation. This enables me to identify the implicit principles connecting standpoint and arguments, by distinguishing the contextual-cultural premises and the general forms of logics necessary to investigate the children's background knowledge and their forms of reasoning. This step constitutes, on one hand, a methodological contribution to the analysis of inferential reasoning in scientific activities and, on the other hand, is a way to deeply investigate the arguments advanced by young children during a problem-solving situation.

The findings of the present study show a predominance of loci from causal relations. A deeper investigation through the AMT showed that children are able to reason about the possibility/impossibility to achieve the goal of an activity in relation to the available tools. The participants of the present investigation were able to reason about valid alternatives to solve a problem, to think about the possible negative consequences of an action, to predict future conditions, and to reason about instruments that prevent reaching a goal. During the scientific activities designed to invite children to solve different problems, the participants were able to change their standpoints during the (short) dialogs, as well as to reason about their premises. They were able to consider, at the same time, their standpoints and the actions of the other speakers. The exploration of the contextual premises in children's argumentation showed how children made explicit their knowledge about physical relationships, as well as the significance of working together and the possibilities of different uses of the available tools.

The present study also suggests that it is possible to shift from the question of how to implement STEM activities in children's education to another level, consisting in identifying what children are already able to do. On the one hand, the attention to how we learn science fostered argumentative analyses in different fields and required the use of various tools. However, the combination of perspectives into an interdisciplinary approach suggests, on the other hand, to think about science not only in purely cognitive terms (for example, the children's focus on correct/incorrect answers) but as a complex network of elements (the different children's cultural background, actions, materials, goals, and forms of reasoning) that strictly depend on the adult's request. For example, the excerpts of interaction presented in this paper belong to the same triad of 
children: accordingly, it could be interesting to further investigate some contextual elements such as the socio-cultural background of the participants and the relationships with the educators, in order to account for the complexity of each situation.

Further studies and more in-depth analyses of these aspects will favor a better understanding of the interplays of cognition, verbal interactions, and tools within scientific activities involving young children. Taking into account the benefits of different approaches and perspectives and combining them in useful ways will contribute to better understand how STEM should be analyzed and how knowledge about science should be explored. The study of the implicit inferential reasoning emerging in situations in which preschool children are asked to solve together a task was a preliminary step to contribute to this promising avenue of research.

Acknowledgements I would like to thank Antonio Iannaccone, Anne-Nelly Perret-Clermont, Sara Greco, Andrea Rocci, Rebecca Schär, and the members of the Institute of Argumentation, Linguistics and Semiotics (Università della Svizzera italiana) for the discussions about the analyses of children's argumentative inferences. I am grateful to the Swiss National Science Foundation for supporting the project n. 100019_156690 "Analysing children's implicit argumentation: Reconstruction of procedural and material premises". For more details: http://p3.snf.ch/project-156690

Funding Information Open access funding provided by University of Applied Sciences and Arts of Southern Switzerland (SUPSI).

\section{Appendix}

\section{Transcription symbols adopted in the excerpts}

\begin{tabular}{ll}
\hline$(0)$ & nonverbal information \\
$(\mathrm{h})$ & laugh \\
$:$ & extension of sound \\
$?$ & rising intonation \\
$\uparrow$ & increasing intonation \\
{[} & overlapping \\
\hline
\end{tabular}

Open Access This article is licensed under a Creative Commons Attribution 4.0 International License, which permits use, sharing, adaptation, distribution and reproduction in any medium or format, as long as you give appropriate credit to the original author(s) and the source, provide a link to the Creative Commons licence, and indicate if changes were made. The images or other third party material in this article are included in the article's Creative Commons licence, unless indicated otherwise in a credit line to the material. If material is not included in the article's Creative Commons licence and your intended use is not permitted by statutory regulation or exceeds the permitted use, you will need to obtain permission directly from the copyright holder. To view a copy of this licence, visit http://creativecommons.org/licenses/by/4.0/.

\section{References}

Åberg, M., Mäkitalo, Å., \& Säljö, R. (2010). Knowing and arguing in a panel debate: Speaker roles and responsivity to others. In K. Littleton \& C. Howe (Eds.), Educational dialogues. Understanding and promoting productive interaction (pp. 13-31). London: Routledge.

Banks-Leite, L. (1998). Langue et argumentation: considérations sur les échanges linguistiques à l'école maternelle. Psychologie de l'interaction, 7-8, 81-100. 
Bova, A., Arcidiacono, F., \& Clément, F. (2017). The transmission of what is taken for granted in children's socialization: The role of argumentation in family interactions. In C. Ilie \& G. Garzone (Eds.), Argumentation across communities of practice: Multi-disciplinary perspectives (pp. 259-288). Amsterdam: Benjamins.

Bybee, R. W. (2013). The case for STEM education: Challenges and opportunities. Arlington: NSTA Press.

Convertini, J. (2019). Contributo allo studio dei tipi di argomento in situazioni di problem solving tecnico da parte di bambini in età prescolare. Doctoral dissertation, University of Neuchâtel, Neuchâtel.

Danish, J. A., \& Enyedy, N. (2015). Latour goes to kindergarten: Children marshaling allies in a spontaneous argument about what counts as science. Learning, Culture and Social Interaction, 5, 5-19.

Duschl, R. A. (2007). Quality argumentation and epistemic criteria. In S. Erduran \& M. P. Jimenez-Aleixandre (Eds.), Argumentation in science education. Perspectives from classroom-based research (pp. 159-175). Dordrecht: Springer.

Duschl, R. A., \& Osborne, J. (2002). Supporting and promoting argumentation discourse in science education. Studies in Science Education, 38, 39-72.

Erduran, S., \& Jiménez-Aleixandre, M. P. (2008). Argumentation in science education. Perspectives from classroom-based research. Dordrecht: Springer.

Erduran, S., Simon, S., \& Osborne, J. (2004). Tapping into argumentation: Developments in the application of Toulmin's argument pattern for studying science discourse. Science Education, 88(6), 915-933.

Greco, S., Perret-Clermont, A.-N., Iannaccone, A., Rocci, A., Convertini, J., \& Schär, R. G. (2018). The analysis of implicit premises within children's argumentative inferences. Informal Logic, 38(4), 438-470.

Grice, H. P. (1975). Logic and conversation. In P. Cole \& J. L. Morgan (Eds.), Syntax and semantics, Vol. 3, Speech acts (pp. 41-58). New York: Academic.

Hannken-Illjes, K., \& Bose, I. (2018). Establishing validity among pre-school children. Journal of Argumentation in Context, 7(1), 1-17.

Iannaccone, A., Perret-Clermont, A.-N., \& Convertini, J. (2019). Children as investigators of Brunerian "possible worlds". The role of narrative scenarios in children's argumentative thinking. Integrative Psychological and Behavioral Science, 53(3), 679-693.

Ibraim, S. D. S., Mendonça, P. C. C., \& Justi, R. D. S. (2013). Contribuições dos esquemas argumentativos de Walton para análise de argumentos no contexto do ensino de ciências. Revista Brasileira de Pesquisa em Educação em Ciências, Belo Horizonte, 13(1), 159-185.

Impedovo, M. A., Delserieys-Pedregosa, A., Jégou, C., \& Ravanis, K. (2017). Shadow formation at preschool from a socio-materiality perspective. Research in Science Education, 47(3), 579-601.

Jefferson, G. (2004). Glossary of transcript symbols with an introduction. In G. H. Lerner (Ed.), Conversation analysis: Studies from the first generation (pp. 13-23). Amsterdam: Benjamins.

Kim, M., Anthony, R., \& Blades, D. (2012). Argumentation as a tool to understand complexity of knowledge integration. In Proceedings of the 2nd international STEM in education conference-Beijing, China (pp. 154-160). Beijing: Beijing Normal University.

Konstantinidou, A., \& Macagno, F. (2013). Understanding students' reasoning: Argumentation schemes as an interpretation method in science education. Science \& Education, 22(5), 1069-1087.

Lazarou, D. (2009). Learning to TAP: An effort to scaffold students' argumentation in science. In Paper presented at the biennial conference of the European science education research association (augustSeptember). Istanbul: Turkey.

Lombardi, E., Greco, S., Massaro, D., Schär, R., Manzi, F., Iannaccone, A., Perret-Clermont, A.-N., \& Marchetti, A. (2018). Does a good argument make a good answer? Argumentative reconstruction of children's justifications in a second order false belief task. Learning, Culture and Social Interaction, 18, 13-27.

Macagno, F., \& Walton, D. (2006). Argumentative reasoning patterns. Paper presented at ECAI 2006 (august 28-September 2), Riva del Garda, Italy.

Macagno, F., \& Konstantinidou, A. (2013). What students' arguments can tell us: Using argumentation schemes in science education. Argumentation, 27(3), 225-243.

Mercer, N. (1995). The guided construction of knowledge. Talk amongst teachers and learners. Clevedon: Multilingual Matters.

Migdalek, M. J., Rosenberg, C. R., \& Santibáñez Yáñez, C. (2014). Estrategias argumentativas en niños pequeños: un estudio a partir de las disputas durante el juego en contextos escolares. Revista Signos, 47(86), 435-462.

Moshman, D. (2004). From inference to reasoning: The construction of rationality. Thinking \& Reasoning, 10, 221-239.

Nonnon, E. (2015). Préface. In N. Muller Mirza \& C. Buty (Eds.), L'argumentation dans les contextes de l'éducation (pp. 1-11). Bern: Peter Lang.

Orsolini, M., \& Pontecorvo, C. (1992). Children's talk in classroom discussions. Cognition and Instruction, 9(2), $113-136$. 
Osborne, J. (2010). Arguing to learn in science: The role of collaborative, critical discourse. Science, 328(5977), $463-466$.

Perret-Clermont, A.-N. (1979/1996). La construction de l'intelligence dans l'interaction sociale. Bern: Peter Lang.

Perret-Clermont, A.-N., Schär, R., Greco, S., Convertini, J., Iannaccone, A., \& Rocci, A. (2019). Shifting from a monological to a dialogical perspective on children's argumentation. Lessons learned. In F. van Eemeren \& B. Garssen (Eds.), Argumentation in actual practice. Topical studies about argumentative discourse in context (pp. 211-236). Amsterdam: Benjamins.

Piaget, J. (1974). La prise de conscience. Paris: PUF.

Piaget, J. (1980). Les formes élémentaires de la dialectique. Paris: Gallimard.

Ravanis, K. (1994). The discovery of elementary magnetic properties in preschool age: Qualitative and quantitative research within a Piagetian framework. European Early Childhood Education Research Journal, 2(2), 79-91.

Rigotti, E., \& Cigada, S. (2004). La comunicazione verbale. Milan: Apogeo.

Rigotti, E., \& Greco, S. (2019). Inference in argumentation: A topical approach to argument schemes. New York: Springer.

Rigotti, E., \& Greco Morasso, S. (2009). Argumentation as an object of interest and as a social and cultural resource. In N. Muller Mirza \& A.-N. Perret-Clermont (Eds.), Argumentation and education. Theoretical foundations and practices (pp. 9-66). New York: Springer.

Rigotti, E., \& Greco Morasso, S. (2010). Comparing the argumentum model of topics to other contemporary approaches to argument schemes: The procedural and material components. Argumentation, 24(4), 489-512.

Rocci, A., Greco, S., Schär, R., Convertini, J., Perret-Clermont, A.-N., \& Iannaccone, A. (2020). The significance of the adversative connectives aber, mais, ma ('but') as indicators in young children's argumentation. Journal of Argumentation in Context, 9(1), 69-94.

Sampson, V., \& Clark, D. (2009). The impact of collaboration on the outcomes of scientific argumentation. Science Education, 93(3), 448-484.

Sanders, M. E. (2008). STEM, STEM education, STEM mania. The Technology Teacher, 68(4), 20-26.

Schwarz, B. B., \& Baker, M. J. (2017). Dialogue, argumentation and education. History, theory and practice. Cambridge: Cambridge University Press.

Smyrnaiou, Z., Petropoulou, E., \& Sotiriou, M. (2015). Applying argumentation approach in STEM education: A case study of the European student parliaments project in Greece. American Journal of Educational Research, 3(12), 1618-1628.

Toulmin, S. (1958). The uses of argument. Cambridge: Cambridge University Press.

van Eemeren, F. H., \& Grootendorst, R. (1984). Speech acts in argumentative discussions: A theoretical model for the analysis of discussions directed towards solving conflicts of opinion. Dordrecht: Floris.

van Eemeren, F. H., \& Grootendorst, R. (2004). A systematic theory of argumentation: The pragma-dialectical approach. New York: Cambridge University Press.

Walton, D. N., Reed, C., \& Macagno, F. (2008). Argumentation Schemes. Cambridge: Cambridge University Press.

Publisher's Note Springer Nature remains neutral with regard to jurisdictional claims in published maps and institutional affiliations. 